\title{
Interdisciplinary Approach to Management of Amelogenesis Imperfecta: A Case Series
}

\author{
Manjunath $\mathrm{SG}^{1}$, Bharathi ${ }^{2}$, Manasa $\mathrm{HD}^{3}$, Betsy S Thomas ${ }^{4}$, Mithun Upadhya ${ }^{5}$, Hema Kanathila ${ }^{6}$
}

\begin{abstract}
Aim: The case series discusses the various interdisciplinary treatment modalities that can be implemented in the management of amelogenesis imperfecta (Al).

Background: Amelogenesis imperfecta is a developmental genetic disorder which affects the deciduous as well as permanent dentition. As prosthetic rehabilitation is very important for esthetics as well as for function, Interdisciplinary approach plays an important role in the management.
\end{abstract}

Case description: Two patients, a 17-year-old female and 16-year-old male, who was diagnosed as cases of Al, were treated with an interdisciplinary approach. After restoring the oral hygiene and carious lesions, fixed partial dentures was given in both the cases and followed up for 8 years.

Conclusion: The management of Al involves careful planning and a stepwise with the most conservative treatment option. Maintenance program aimed at preventive care adds to the success in the rehabilitation of such cases.

Clinical significance: Early diagnosis and careful treatment planning play an important role in the success of this case. Patient age should be kept in mind as long term prognosis should be our primary aim in treating Al cases.

Keywords: Amelogenesis imperfecta, Comprehensive, Hereditary, Interdisciplinary, PFM, Zirconia.

World Journal of Dentistry, (2019): 10.5005/jp-journals-10015-1622

\section{INTRODUCTION}

A melogenesis is a process where initially a protein-rich matrix is formed during the secretory phase of teeth development and then followed by a mineralization phase where these proteins are replaced by hydroxyapatite crystals. Amelogenesis imperfecta (AI) is a developmental genetic disorder. ${ }^{1}$ It affects the enamel causing various structural defects resulting in a range of clinical phenotypes. ${ }^{1}$ It is known by varied names such as hereditary enamel dysplasia, hereditary brown enamel and hereditary brown opalescent teeth. ${ }^{2}$ According to various studies the prevalence ranges from 1:700 to $1: 14000 .^{3}$ During the secretory stage of teeth development a rich protein matrix is formed (a process called as amelogenesis). In the secretory phase of enamel formation, the enamel matrix proteins secreted by ameloblasts play a role in the growth of enamel crystal. After the secretory phase, is the mineralized phase where the proteins formed are replaced by crystals (HA). According to the various studies, Al is caused by a mutation in AMELX (amelogenin gene) and ENAM (enamelin gene).

Various classification systems are based on genetic heritance, histopathology and specific clinical characteristics, which involves various dental anomalies including discolored teeth, microdontia, congenitally missing teeth, taurodontism, pulpal calcification, hypercementosis, crown, and root resorption.,2,4-13 Additionally it may also be associated with malocclusions such as open bite and crossbite. ${ }^{13-15}$ An anterior open bite can result due to defect in eruptive mechanism secondary to disturbances of the enamel epithelium. According to other reports, the anterior open bite results from tongue thrusting and thumb sucking habits. ${ }^{16}$

Children with Al have a variety of oral difficulties including increased incidence of caries, delayed tooth eruption, or even teeth retention, the sensitivity of teeth, loss of occlusal vertical dimension, unsatisfactory aesthetics. ${ }^{17-19}$ Due to unsatisfactory esthetics the subjects may also have a psychological related problem and lack \begin{tabular}{l}
\hline \hline 1-3 Department of Periodontology, Subbaiah Institute of Dental \\
Sciences, Shivamoga, Karnataka, India \\
${ }^{4}$ Department of Periodontology, Faculty of Dentistry, MAHSA \\
University, Jenjarom, Kuala Langat, Selangor, Malaysia \\
${ }^{5}$ Department of Prosthodontics, AJ Institute of Dental Sciences, \\
Kuntikhana, Mangaluru, Karnataka, India \\
${ }^{6}$ Department of Prosthodontics, KAHERs KLE VK Institute of Dental \\
Sciences, Belagavi, Karnataka, India
\end{tabular}

Corresponding Author: Manjunath SG, Department of Periodontology, Subbaiah Institute of Dental Sciences, Shivamoga, Karnataka, India. e-mail: sgman2K@gmail.com

How to cite this article: Manjunath SG, Bharathi, Manasa HD, Thomas BS, Upadhya M, Kanathila H Interdisciplinary Approach to Management of Amelogenesis Imperfecta: A Case Series. World J Dent 2019;10(2):150-153.

Source of support: Nil

Conflict of interest: None

of self-confidence. ${ }^{17}$ All this leads to certain difficulties in managing such cases. $^{20}$

Since Al affects deciduous as well as permanent dentition, a specific preventive and restorative approach is needed to handle such cases. ${ }^{20}$ Depending on the age and clinical presentation during the initial visit, a team approach is initiated in the transitional phase of treatment. In the case of children, the role of pediatric dentist varies from reassurance to child and parents, to provide support and motivation, towards the maintenance of good oral hygiene. Such cases are then followed up by a restorative dentist to provide for proper maintenance of patients dentition. The common challenges faced by restorative dentists are poor oral hygiene resulting in inflammation around the teeth, sensitivity, caries, discoloration, loss of vertical dimensions, reduced inter root space, large pulp to crown

(c) The Author(s). 2019Open Access This article is distributed under the terms of the Creative Commons Attribution 4.0 International License (https://creativecommons. org/licenses/by-nc/4.0/), which permits unrestricted use, distribution, and non-commercial reproduction in any medium, provided you give appropriate credit to the original author(s) and the source, provide a link to the Creative Commons license, and indicate if changes were made. The Creative Commons Public Domain Dedication waiver (http://creativecommons.org/publicdomain/zero/1.0/) applies to the data made available in this article, unless otherwise stated. 
ratio, decreased bond strength of resin to enamel and bonding to enamel due to rapid loss of enamel. ${ }^{20}$ The treatment options mainly depend on patient factors (age, socioeconomic status) as well as Comprehensive dental management.

Most of the patients reporting to the clinic are the ones who seek quick results that help them amalgamate with their peers fast. Various restorative options include the use of adhesive restorative techniques, overdentures, porcelain-fused to metal crowns, FPD, full porcelain crowns, inlay/onlay restorations and lately zirconium crown. ${ }^{17-19,21-25}$ This the paper highlights the interdisciplinary management of patients with Al. Two clinical cases are described to illustrate this.

\section{Cases}

\section{Case 1}

A female patient aged 17 years reported to our clinic (located in Rajajinagar, Bengaluru) with a chief complaint of discolored brown teeth and unesthetic appearance. This discoloration according to the parents was noticed since early childhood. Medical history was noncontributory. On clinical examination, we could appreciate the brownish discoloration of the existing teeth with no pulpal changes. The clinical crown length was adequate with thick gingival biotype. Lower right first molar showed caries with pulpal involvement. In this case, the esthetic challenge was posed to the treatment outcome due to surface roughness, staining, and abnormal crown shapes. Plaque retention on the rough surface, as well as marginal inflammation, added to the existing aesthetic challenges.

The treatment plan was discussed with the patient keeping in mind the esthetic priority. Upper right lateral incisor which was palatally placed was recommended for extraction in order to facilitate fabrication of a bridge. The importance of oral hygiene in the long-term maintenance of the dentition was emphasized in the initial visit. Consent was obtained for the treatment from the parents, as the patient was below 18 years. Oral hygiene was improved and the patient was counseled regarding the poor diet control and its devastating effects on both unrestored and restored teeth. This was followed by the restoration of caries lesions. The right lower first molar which was decayed with pulpal involvement was subjected to root canal therapy. Once the oral hygiene was improved and the gingival condition was stabilized, the restorative management was initiated.

A diagnostic wax-up of the proposed restoration was discussed with the patient. All the teeth mesial to second molars were prepared for porcelain fused metal fixed partial denture (3 unit bridges connecting premolars and first molar, so we have four 3 unit bridges of PFM connecting right and left premolars and the first molar on the maxillary and mandibular posterior region and two 6 unit bridges connecting the canines and incisors both in maxillary and mandibular anterior region). The prosthesis was fabricated and cemented. A similar treatment was also carried out for the lower teeth. Regular follow up was initiated with a maintenance program initially once in 3 months which later changed to once in 12 months.

During the prosthetic treatment part, Case 2 had accompanied the Case 1 with a similar complaint (a family history was taken from case (Fig. 1) during the initial visit and no similar history in any other family members was reported by the patient or the patient party) (Fig. 2). The postoperative pictures of this case are numbered (Fig. 3) and the OPG is numbered 3A).

\section{Case 2}

A 16-year-old male patient who is a close relative of Case 1 , presented with similar chief complaint of discoloration of teeth from early childhood. But the intensity of discoloration, in this case, was lesser compared to Case 1. Treatment plan and options were discussed with the patient and patient opted for zirconia crown and bridge. The treatment plan was initiated after attaining satisfactory oral hygiene.

Both the cases were followed up for 8 years (the preoperative photographs of Case 2 is numbered (Fig. 1), the postoperative photographs as (Fig. 2B) and the OPG are numbered as (Fig. 3B).

\section{Discussion}

Amelogenesis imperfecta affects the teeth in the developmental stage, leading to delayed tooth eruption and changes in crown morphology. This enamel structure and clinical appearance are affected by the condition and may also be associated with biochemical/morphological changes elsewhere in the body. ${ }^{26,27}$ Diagnosis of Al follows after a thorough examination of the family history, pedigree plotting, and clinical observation. Pedigree plotting is a diagram that shows the occurrence and appearance or phenotypes of a particular gene from one generation to the next, but this technique did not use in the diagnosis of this particular case series. Radiographic examination, aids in assessing the density of enamel and deciding the treatment options. The genetic mutations can occur by either autosomal or X-linked dominant or recessive modes of inheritance. ${ }^{18,27}$ The autosomal dominant $\mathrm{Al}$ is reported most frequently in Europe and North America and the recessive forms in regions where consanguineous marriages are common like in the Turkish population. ${ }^{27}$ The various another differential diagnosis can include the environmental enamel hypoplasia, dentin dysplasia, regional odontontodysolasia. Based on the history, clinical examination and hereditary component a diagnosis of Al was arrived at with respect to both the cases.

Dental treatment becomes necessary in the case of Al as the defective teeth are prone to damage and breakage. Some patients experience emotional and social issues including depression and low self-esteem.

The management of $\mathrm{Al}$ is quite different from the management of other cases because of the diverse component involved like the familial/genetic component, the socioeconomic status, and age to name a few. At present, there is no standard treatment

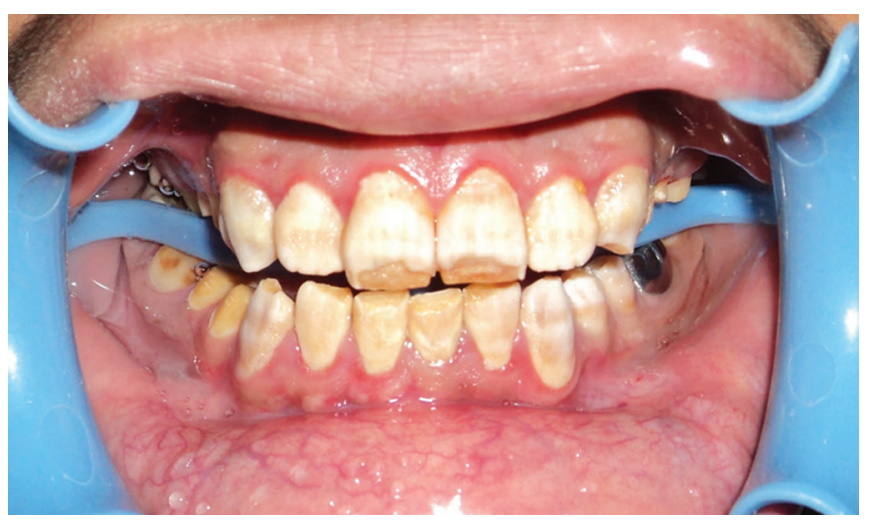

Fig. 1: Preoperative photograph of case 2 prior to the start of the treatment procedures depicting the involvement of the teeth along with the oral hygiene status. In this case the involvement was observed more with respect to the $11,21,31,32,41,42$ and the posterior teeth.The enamel defects were lesser in this case as compared to Case 1 

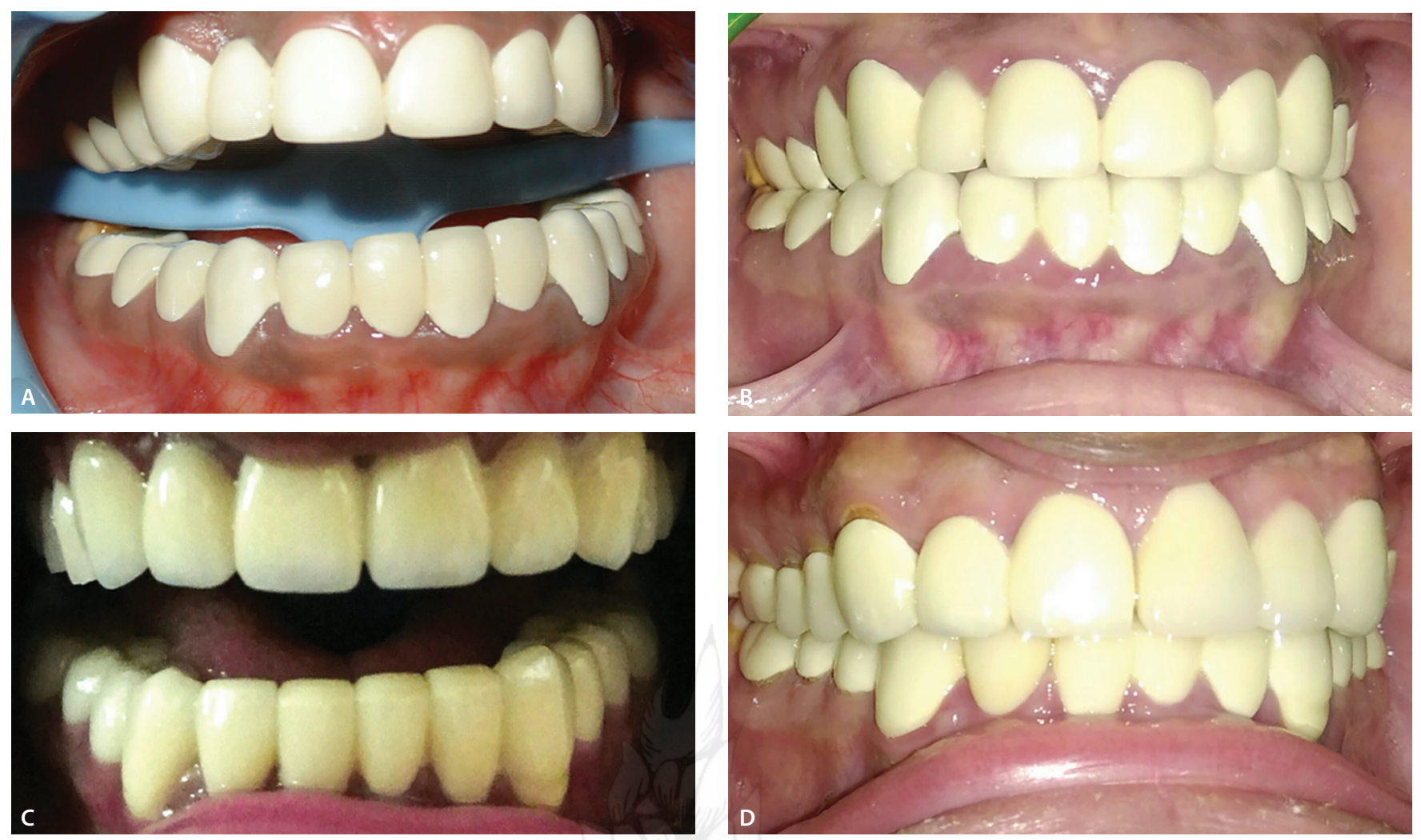

Figs $2 \mathrm{~A}$ to $\mathrm{D}$ : (A and B) Case 1 postoperative photograph after the rehabdilitation and after 8 years follow-up visit depicting the oral hygiene status and maintenance by the patient during the follow up period; ( $C$ and $D)$ Case 2 postoperative photographhafter rehabilitation and at 8 th year follow-up depicting a well maintenance by the patient of the the oral hygiene status and the prosthesis
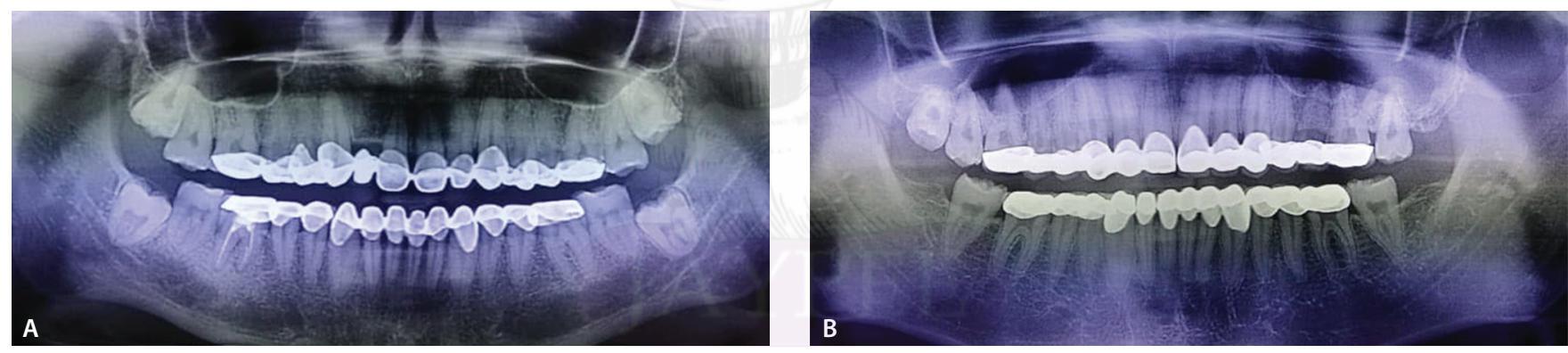

Figs 3A and B: (A) Postoperative OPG of Case 1 depicting the RCT done with respect to 46; (B) Postoperative OPG case 2

for Al and the treatment options depend mainly on the type and severity of the condition and also the age of the patient. Restoring the esthetics as well as function is the most challenging aspect of the treatment. ${ }^{27}$ Moreover, such condition usually requires an extensive treatment which poses a significant financial burden for the person and the family.

Various studies have described the use of restorative and esthetic treatment care in Al patients. ${ }^{26}$ Restorative treatment options included composite resin veneers, stainless steel crowns, adhesive castings, overdentures, porcelain veneers, and ceramics. ${ }^{27}$ Stainless steel or $\mathrm{NiCr}$ crowns have also been used for both primary and permanent molars since these effectively reduce sensitivity and maintain the vertical dimension of occlusion. ${ }^{12}$ These temporary restorations provide esthetic and protective features with minimal preparation and allow normal development of the dentition and help in the unimpaired eruption of teeth.
In the management of $\mathrm{Al}^{3}$ distinct aspects of treatment which needs to be focused on are the following:

- Prevention

- Restoration

- Esthetics

Preventive aspects include dietary advice on limited sugar intake and nonerosive diet, fluoride supplements and oral hygiene maintenance. ${ }^{16}$ The periodontal health and eruptive process are important for the success of the restorative treatment. And if any restoration margins become visible, then additional treatment will be required at regular follow-up intervals. ${ }^{19}$

The prosthodontic treatment options also vary according to the type of dentition. In primary dentition, minimal interventions like GIC restorations, direct and indirect composite resin are used. Veneers are a good option in mixed dentition compared to full crowns but porcelain veneers, full crowns, overdentures, and complete dentures are preferred in permanent dentition. $4,16,23,25,27$ 
The option of extraction and construction of complete or removable partial dentures in $\mathrm{Al}$, affects the psychological status of the adolescent patients and should be dealt with utmost care. $^{4,22,24,27}$

\section{Conclusion}

Management of patients with Al requires careful planning and requires a stepwise approach with most conservative treatment options first. A comprehensive model of management involving specialties of pediatric, surgical and orthodontic disciplines are essential. The treatment should be focussed towards prolonging the life of patients own teeth and to avoid or delay the need for further restorative options. The role of primary care and the long term preventive care maintenance program definitely add to the success story of every case.

\section{References}

1. Herath EM, Jayasooriya PR, Perera IR. Descriptive analysis of subtypes of Amelogenesis Imperfecta. Srilanka Dental Journal 2011;41:17-25.

2. Patel A, Chaudhary AR, Dudhia B, et al. Amelogenesis Imperfecta. The Journal of Ahemdabad Dental College and Hospital 2011;2(1):39-44.

3. Nigam P, Singh VP, Prasad K, et al. Amelogenesis Imperfecta -A Review.J Adv Med Dent Scie Res 2015;2(3):83-90.

4. Rao S, Witkop CJ. Inherited defects in tooth structure. Birth defects. Orig Artic See 1971;7:153-184.

5. Winter GB, Brook AH. Enamel hypoplasia and anomalies of enamel. Dent Clin North Am 1975;19:3-24.

6. Witkop CJ. Herditary defects in enamel and dentin. Acta Genet Stat Med 1957;7:236-239.

7. Aldred MJ, Crawford PJ. Variable expression non Amelogenesis Imperfecta with taurodontism. J Oral Pathol 1988;17:327-333.

8. Collins MA, Mauriello SM, Tyndall DA, et al. Dental anomalies associated with Amelogenesis Imperfecta: A radiographic assessment. Oral Surg Oral Med Oral Pathol Oral Radiol Endod 1999;88:358-364

9. Aldred MJ, Savarirayan R, Lamanda SR, Crawford PJ. Clinical and radiographic features of a family with autosomal dominant Amelogenesis Imperfecta with taurodontism. Oral Dis 2002;8:62-68.

10. Auers KM, Drummond BK, Hurding WJ, et al. Amelogenesis Imperfecta multidisciplinary management from eruption to adulthood. Review and case report. NZ Dent J 2004;100:101-104.

11. Kormacher HM, Lemke R, Kahl-Nicke B. Progressive Preeruptive crown resorption in autosomal recessive generalised hypoplastic
Amelogenesis Imperfecta.Oral Surg Oral Med Oral Pathol Oral Radiol Endod 2007;104:540-544.

12. Suchancova B, Holly D, Janska $M$, et al.Amelogenesis Imperfecta and the treatment plan. Interdisciplinary team approach. Bratisl Leklisty 2014;115:44-48.

13. Koruyucu M, Bayram M, Tuna E, et al. Clinical findings and long -term managements of patients with Amelogenesis Imperfecta. Eur J Sent 2014;8(4);546-552.

14. Kida M, Ariga T, Shirkawa T, et al. Autosomal dominant Hypoplastic form of Amelogenesis Imperfecta caused by enamel in gene mutation at the exon-intron boundary. J Dent Res 2002;81:738-742.

15. Kidaord PJ, Aldred MJ. X linked Amelogenesis Imperfecta. Presentation of two kinds and a review of the literature. Oral Surg Oral Med Oral Pathol 1992;73:449-455.

16. Mahesh KP. Amelogenesis Imperfecta. Int J Health Allied Sci 2012;1(4):283-285.

17. Yip HK, Smales RJ. Oral rehabilitation of young adults with Amelogenesis Imperfecta. Int J Prosthodont 2003;16:345-349.

18. Rathi NV, Singh MG, Kumar M, et al. Oral rehabilitation of Amelogenesis Imperfecta: A case report. Indian J Dent Sci 2013;3:64-66.

19 Mc Donald S, Arkutu N, Malik K, et al. Managing the paediatric patients with Amelogenesis Imperfecta. Br Dent J 2012;212:425-428.

20. Gokce K, Canpolat C, Ozel E. Restoring Function and esthetics in a patient with Amelogenesis Imperfecta. A case report. J Contemp Dent Pract 2007;8:95-101.

21. Ozturk N, Sari Z, Ozturk B. An interdisciplinary approach for restoring function and esthetics in a patient with Amelogenesis Imperfecta and malocclusion:A clinical report. J Prosthet Dent 2004;92: 112-115.

22. Neto NL, Paschoal MA, Kobayashi TY, et al. Early oral rehabilitation of a child with Amelogenesis Imperfecta. J Health Sci Inst 2010;28:246248.

23. Witkop CJ, Sauk JJ Jr. Heritable effects of enamel. Oral facial genetics. St Louis: CV Mosby 1976:151-226.

24. Bsoul SA, Klint DJ, Terezhalmy GT, et al. Amelogenesis Imperfecta. Quinteissence Int 2004;35:338-339.

25. Chosack A, Eidelman E, Wisotski I, et al. Amelogenesis Imperfecta among Israeli Jews and the description of a new type of local hypoplastic autosomal recessive Amelogenesis Imperfecta. Oral Surg Oral Med Oral Pathol 1979;47(2):148-156.

26. Markovic D, Petrovic B, Pericardial T. Case series: Clinical findings and oral rehabilitation of patients with Amelogenesis Imperfecta. Eur Arch Paediatric Dent 2010;11:201-208.

27. Ayers KM, Drummond BK, Harding WJ, et al. Amelogenesis ImperfectaMultidisciplinary management from eruption to adulthood.Review and case report. NZ Dent J 2004;190:101-104. 